Results 25 colleagues were trained including 17 junior doctors, 3 consultants and 3 advanced neonatal nurse practitioners (23 feedbacks received).

All of the them fedback that the session fully met their professional needs.

Everybody (23) felt that the integration of theory and practical in this way was excellent.

3 participants did not have any opinion about using the animal model. One person did not like the idea of animal model (religious reasons).

Conclusion A rabbit model for chest drain training was found to be extremely useful to majority of our trainees. This type of training should be arranged once every 6 months with the changing team of junior doctors.

\section{CAUSE OF RESPIRATORY DISTRESS IN NEONATAL INTENSIVE CARE UNIT: A RETROSPECTIVE EVALUATION}

doi:10.1136/archdischild-2012-302724.1774

${ }^{1} \mathrm{~A}$ Annagür, ${ }^{2} \mathrm{H}$ Altunhan, ${ }^{3} \mathrm{~S}$ Arıbaș, ${ }^{3} \mathrm{M}$ Konak, ${ }^{3} \mathrm{R}$ Örs. 'Department of Neonatology, Selcuk University, Selcuklu Medical Faculty, Konya; ${ }^{2}$ Department of Neonatology, Abant Izzet Baysal University, Medical Faculty, Bolu; ' ${ }^{3}$ Department of Neonatology, Konya University, Meram Medical Faculty, Konya, Turkey

Purpose To determine the demographic characteristics of the newborns with respiratory difficulties, frequency of neonatal disease, analyze of the prognostic factors and effectiveness of treatment who were hospitalized in NICU of our hospital between 2008 and 2009.

Methods In this study, file records of the newborns who were hospitalized in NICU of Selcuk University, Meram Medical School were analyzed retrospectively.

Results Of the 771 newborns, 225 who admitted due to respiratory distress in 2008 and of the 692 newborns, 282 who admitted due to respiratory distress in 2009. Mean birth weight was $1954 \pm 972 \mathrm{gr}$ in 2008 , and $2140 \pm 1009 \mathrm{gr}$ in 2009. Mean pregnancy weeks were $32.4 \pm 5.0$ in 2008 and $33.4 \pm 4.9$ in 2009. Diagnosis of patients were sepsis $(77.8 \%)$, respiratory distress syndrome (RDS) (40.4\%), pneumothorax (20.9\%), patent ductus arteriosus (PDA) $(12.4 \%)$, meconium aspiration syndrome (MAS) (6.2\%), intraventricular hemorrhage (IVH) (5.3\%), pneumonia (3.6\%), retinopathy of prematurely (ROP) (3.1\%), bronchopulmonary dysplasia (BPD) $(2.7 \%)$ and transient tachypne of newborn (TTN) $(2.2 \%)$ in 2008 . In 2009 , percentage of the diagnosis was $69.5 \%$ sepsis, $33.3 \%$ RDS, $17.0 \%$ PDA, $16.0 \%$ pneumothorax, $10.3 \%$ pneumonia, $8.2 \%$ IVH, $6 \%$ TTN, $5.3 \%$ BPD, $3.2 \%$ MAS and $3.2 \%$ ROP. $33.7 \%$ of the patients were died in 2009 and $43.6 \%$ of them in 2008.

Conclusion The newborns with respiratory distress who admitted to the hospital must be evaluated according to the pregnancy week, way of birth and accompanying problems during first examination and convenient transportation of the ones who need to be cared in advanced center where an intensive care support can be applied to decrease mortality and morbidity of newborns distress.

\section{THE EVALUATION OF LUNG FUNCTION MEASURED BY IMPULSE OSCILLOMETRY METHOD IN VERY LOW BIRTH WEIGHT BORN CHILDREN AT PRESCHOOL AGE}

doi:10.1136/archdischild-2012-302724.1775

'M Oruç, 'A Günlemez, ${ }^{2} Z S$ Uyan, 'AS Gökalp, 'N Kavas, ' $\mathrm{G}$ Türker, 'AE Arısoy. 'Neonatology; ${ }^{2}$ Pediatric Pulmonology, Kocaeli University, Kocaeli, Turkey

Chronic lung disease is one of the most important complications of prematurity and results in short and long-term morbidity. Survival of more prematurely born babies leads to an increase in the incidence of bronchopulmonary dysplasia (BPD).
The Aim of this study is to evaluate the lung function of babies who were born under birth weight of 1500 grams using impulse oscillometry in preschool age.

Eighty-six children who were 3-6 years old and followed in our neonatology clinic (born under birth weight of 1500 grams) were enrolled in the study as the patient group and 40 term-born healthy children as the control group. The demographic data of the patients, duration of mechanical ventilation and oxygen therapy and presence of BPD were recorded. After routine physical examination, lung functions of the patients were measured by impulse oscillometry. The data were evaluated by SPSS 16 program.

Forty-nine $(57 \%)$ of 86 patients were non-BPD, 20 were mild $\mathrm{BPD}, 14$ were moderate $\mathrm{BPD}$ and 3 were severe $\mathrm{BPD}$.

Weight and height of pramature and control groups were similar. There was a statistically significant difference between the two groups in terms of resistance (R5, R10, R20), reactance (X5, X10, $\mathrm{X} 20$ ) and resonant frequency (fres). The airway resistance was significantly higher and reactance was significantly lower in the premature group. However, there was no difference between BPD and non-BPD groups.

In conclusion; although premature babies can catch-up their peers at 3-4 years old in terms of their body percentiles, their lungs still reflect the traces of prematurity.

\section{RESPONSE THRESHOLDS TO PULSE OXIMETRY ALARMS IN THE NICU - AN OBSERVATIONAL STUDY}

doi:10.1136/archdischild-2012-302724.1776

1,2K Tan, ${ }^{2} \mathrm{~A}$ Clarke, ${ }^{2} \mathrm{P}$ Berger, ${ }^{2} \mathrm{E}$ Skuza, ${ }^{1,2} \mathrm{~A}$ Ramsden. 'Monash Newborn, Monash Medical Centre; ${ }^{2}$ Ritchie Centre, Monash Institute for Medical Research, Monash University, Melbourne, VIC, Australia

Background and Aims Manual control of oxygen delivery to premature infants is conducted mainly by NICU nurses. This involves $\mathrm{F}_{1} \mathrm{O}_{2}$ adjustments in order to keep the $\mathrm{S}_{\mathrm{p}} \mathrm{O}_{2}$ within a specific target range (88-92\%). Pulse oximeters have alarms set to alert the nurses when $\mathrm{S}_{\mathrm{p}} \mathrm{O}_{2}$ values are outside the range (85-95\%). Our aims were to study $\mathrm{F}_{\mathrm{I}} \mathrm{O}_{2}$ alteration in terms of magnitude and time outside target immediately before the $\mathrm{F}_{\mathrm{I}} \mathrm{O}_{2}$ change.

Methods Infants receiving CPAP or ventilation on the Babylog 8000 ventilator (Dec 2010- Apr 2012) were studied. Signals were acquired from oximeters and ventilator using the PowerLab data acquisition system. The 9-minute epoch prior to each $\mathrm{F}_{\mathrm{I}} \mathrm{O}_{2}$ change: $\mathrm{F}_{\mathrm{I}} \mathrm{O}_{2}$ increase $(\Delta \mathrm{POS})$ and $\mathrm{F}_{\mathrm{I}} \mathrm{O}_{2}$ decrease $(\Delta \mathrm{NEG})$ were studied.

Results Recordings were obtained from 7 (5 male) infants with mean $( \pm$ SD) gestation of $26.9( \pm 1.9)$ weeks and birthweight 767 $( \pm 200)$ g. $253 \mathrm{~F}_{\mathrm{I}} \mathrm{O}_{2}$ adjustments were recorded (130 $\Delta \mathrm{POS}$ and 123 $\triangle \mathrm{NEG}$ ) from 105 hours of total recording time. Mean (range) magnitude of $\triangle \mathrm{POS}$ and $\triangle \mathrm{NEG}$ was $4.6 \%(0.5-19.5)$ and $4.5 \%(0.5-57.0)$ respectively. Proportion time spent with low alarm in the 9 minutes before $\triangle \mathrm{POS}$ was $50.8 \%$, with $28.4 \%( \pm 20.2)$ of time in $80-85 \%$, $15.8 \%( \pm 16.7)$ in $70-80 \%$ band and $6.6 \%( \pm 11.3)$ less than $70 \%$ saturation. $22.5 \%$ of time was spent with high alarm (before $\Delta \mathrm{NEG)}$ with $4.3 \%( \pm 8.7)$ time $\mathrm{S}_{\mathrm{p}} \mathrm{O}_{2}$ exceeding $98 \%$ and $7.7 \%( \pm 11.4)$ in 96-98\% band.

Conclusion Nurses were more likely to tolerate low oxygen saturations than high saturations in preterm infants. Mild desaturation episodes (between 80-85\%) were often managed conservatively. 